DIRECTOR DEPARTAMENTO DE DISEÑO

FACULTAD DE ARQUITECTURA Y URBANISMO

UNIVERSIDAD DE CHILE

\section{Palabras del director}

\author{
Words From the Director
}

Hoy volvemos a poner en circulación un nuevo número de la revista RChD: creación y pensamiento. Se ha realizado con gran esfuerzo y responsabilidad de un grupo de académicos que cree relevante este proyecto para la disciplina. No obstante, aún nos queda mucho por avanzar para cumplir con uno de sus principales objetivos: su indexación. Esto supone, claro, un compromiso urgente con el desarrollo de la enseñanza del Diseño tanto en el campo de la didáctica, como en el mundo profesional y, además, con un compromiso con lo social.

Esta edición trae consigo artículos que dan cuenta de temas disímiles, con un aporte a la temática del color, producto de las repercusiones que tuvo el Congreso Internacional: Color en la Vida Urbana, realizado hace unos meses en Santiago de Chile. Esta diversidad nos indica que el Diseño tiene muchas variantes y temas por tratar y que no podemos dejar de ponerlos en lo público. Estas investigaciones y reflexiones buscan dar valor a diversos aspectos: el Pop catalán, la gestión, el color y el retail, la enseñanza del color en Chile y el diseño de resistencia por nombrar algunos de los artículos que se incluyen en esta edición.

Los apartados en circulación responden, como lo dice el mismo nombre de la revista, a pensar en torno a la creación en Diseño y qué significa, ampliar su campo de acción, así como también, pensar el Diseño, extendiendo sus límites tradicionales del hacer, hacia nuevas configuraciones en una sociedad que evoluciona velozmente y trae consigo diversos desafíos, además del cultivo de la innovación, tanto en la experimentación como en la investigación aplicada, la teoría, la estética, la semiología y otros temas. Desde esta perspectiva estos conceptos se transforman en un hacer reflexivo para dar cuenta de nuestro propósito de construir conocimiento y difundirlo a través de esta revista, en un espíritu colaborativo, tanto de quienes la hacen posible como de aquellos que participan con sus investigaciones. En este sentido es importante reconocer el apoyo de todos quienes han elegido nuestra revista como medio de divulgación pese a que aún no esté indexada, lo cual resaltamos como un acto de generosidad de quienes buscan compartir su conocimiento con los lectores de una publicación relativamente joven, en evolución, a veces postergando la oportunidad de publicar en otros medios más consolidados. Por tanto, es doble el reconocimiento a los colaboradores, que lo han hecho con mística y compromiso por nuestra disciplina.

Finalmente, solo resta hacer un llamado a los investigadores y creadores para que sigan colaborando y contribuir así a que este sea un proyecto de interés para la comunidad del Diseño y de otras disciplinas afines, con lo cual podremos seguir construyendo un discurso tanto a nivel nacional como internacionalmente. 